\title{
Barbiturates Versus Benzodiazepine for the Treatment of Severe Alcohol Withdrawal Syndrome: A Systematic Review and Meta- Analysis of Clinical Trials
}

\author{
Blerina Asllanaj ( $\square$ blerina.asllanaj@hcahealthcare.com ) \\ HCA Healthcare, MountainView Hospital \\ Eric Chang \\ HCA Healthcare, MountainView Hospital \\ Maha Hassan \\ MAP Centre for Urban Health Solutions, St. Michael's Hospital, Toronto \\ Yi McWhorter \\ HCA Healthcare, MountainView Hospital
}

\section{Research Article}

Keywords: Alcohol withdrawal syndrome, delirium tremens, seizure, benzodiazepine, phenobarbital, barbiturate, systematic review, meta-analysis

Posted Date: December 13th, 2021

DOl: https://doi.org/10.21203/rs.3.rs-1121796/v1

License: @ (i) This work is licensed under a Creative Commons Attribution 4.0 International License. Read Full License 


\section{Abstract}

Context: The utility of phenobarbital in the treatment of severe alcohol withdrawal is contentious.

Objective: The aim was to conduct a meta-analysis of existing observational and randomized controlled trials investigating the efficacy and safety of phenobarbital versus commonly used benzodiazepine in the setting of severe alcohol withdrawal.

Data Sources: A search of PubMed, Medline, Embase, and the Cochrane Central Register of Controlled Trials published between 1976 and September 2021 was performed using medical subject headings: "severe alcohol withdrawal", "delirium tremens" (DT), "phenobarbital" (PB), "barbiturate”, "critical care”, “ICU”, "Trial”, "human” and "English”. We selected English-language clinical trials (observational and randomized controlled trials (RCT)) evaluating the efficacy and safety of phenobarbital (PB) compared to benzodiazepine (BZD) for the treatment of severe alcohol withdrawal syndrome (AWS) in the acute care setting.

Study Appraisal and synthesis methods: Data extraction and critical appraisal were carried out independently by two authors (EC and YM) using predefined data fields. The outcome variables analyzed included (a) history of DT; (b) initial CIWA-AR score; (c) drug dosages delivered; (d) duration of medical treatment of severe AWS; (e) other adjunct medication use; (f) intensive care unit (ICU) length of stay (LOS); (g) hospital LOS; (h) readmission rate; (i) DT or seizures; (j) other complications including endotracheal intubation and mechanical ventilation. These outcomes were unanimously decided to be important as they influence the practical management of severe AWS within hospitals and institutions. Heterogeneity amongst the outcome variables of these trials was determined by Cochran's $Q$ statistics and $\mathrm{I}^{2}$ index. The meta-analysis was prepared in accordance with PRISMA guidelines.

Results: Seven studies consisting of 1 prospective RCT and 6 retrospective trials were identified. Results from all the included studies show similar variables between BZD and PB group: mean age, percentage of patients with previous DT, and median Clinical Institute Withdrawal Assessment for Alcohol Revised (CIWA-AR) scores. There were no statistically significant differences in ICU and hospital LOS when comparing the BZD and PB groups. The prevalence of DT and adjunct medication usage was higher in the BZD group; however, statistically insignificant in the meta-analysis. The pooled prevalence of intubation was similar between the two treatment groups. Lastly, Hawa et al. reported higher alcohol-related re-admission in the BZD group.

Conclusions: Based on our findings, the use of PB as the primary treatment, or when used in addition/as adjunct to BZD, offers several advantages in the treatment of severe AWS. These include trend toward improved DT and seizures in severe AWS, shortened ICU and hospital LOS, and less use of adjunct medications. Further RCTs are needed to investigate PB as the primary treatment of AWS that presents with severe features.

\section{Introduction}

Globally, alcohol misuse is the seventh-leading risk factor for premature death and disability [1]. It's estimated that two to seven percent of patients with heavy alcohol use admitted for general medical care develop severe alcohol withdrawal syndrome (AWS) [2]. Abrupt cessation of alcohol after chronic use causes a disturbance between inhibitory neurotransmitter GABA (y-aminobutyric acid) and excitatory neurotransmitter NMDA (N-methyl-D-aspartate) responses. Without the presence of alcohol, the disruption of neuronal-chemical balance leads to a lack of inhibitory neurotransmitter activity, which leads to the clinical manifestation of alcohol withdrawal symptoms. Mild withdrawal symptoms, including insomnia, diaphoresis and gastrointestinal upset, will appear within six hours of the most recent alcoholic drink. Seizures will appear within twelve hours after the last drink in patients with an extensive history of heavy alcohol consumption. The mortality rate from AWS is estimated to be $20 \%$ if left untreated [3], and reduced up to $5 \%$ with early recognition and treatment.

The assessment and management of patients with alcohol withdrawal is widely based on the Clinical Institute Withdrawal Assessment- Alcohol Revised (CIWA-AR) scale. This protocol is beneficial in individualizing treatments, reducing both treatment duration and the amount of medications used [4]. AWS is managed with standardized administration of benzodiazepines (BZD), supportive care and continuous evaluation using the CIWA-AR scale [5]. The CIWA-AR based administration of BZD is recommended by addiction specialists due to its favorable therapeutic effect index. The effectiveness of BZD for the management of AWS has been demonstrated in multiple studies in improving the symptoms of withdrawal and lowering the risk of progression 
to DT [6]. However, some patients develop tolerance, which increases their risk of rebound withdrawal symptoms. In addition, the administration of BZD may cause over sedation and encephalopathy in hospitalized patients [7].

In cases of refractory or more severe form of AWS, decreased GABA receptor sensitivity to GABA agonists may cause BZD to be ineffective [8]. Alternatively, a barbiturate such as phenobarbital (PB), can be used as monotherapy or adjunct treatment to control refractory symptoms. BZD acts on GABA receptor by increasing the frequency of chloride channel opening. Barbiturates not only increase the duration of GABA channel opening, but also reduces glutamate release via AMPA and kainite receptor, which reduce the incidence of cross-tolerance [9]. This systematic review and meta-analysis serve to compare and contrast the use of PB versus BZD in severe AWS in acute care settings, examining their effectiveness and safety profile.

\section{Materials \& Methods}

Search strategy and data collection: We conducted comprehensive search of electronic databases in PubMed, Medline, Embase and the Cochrane Central Register of Controlled Trials published between January 1976 and September 2021 using medical subject headings: "severe alcohol withdrawal", "delirium tremens" (DT), "phenobarbital" (PB), "barbiturate", "critical care", "ICU", "Trial”, "human" and "English". We further searched the reference lists of all included primary studies and existing meta-analysis for additional suitable manuscripts. The study protocol was designed by appraising the quality of identified trials and extracting and analyzing meaningful data by two authors (YM and EC) independently. The authors were not blinded to the source of the document or authorship for the purpose of data extraction. The data were obtained from observational studies and RCT meeting the inclusion criteria, and they were entered directly into Microsoft Excel spreadsheet. Then this information was examined by another independent author (BA), comparing and addressing discrepancies until consensus was reached. The analysis was prepared in accordance with the preferred reporting of systematic reviews and meta-analyses (PRISMA) statement [10].

Inclusion and exclusion criteria: Two authors (YM and EC) individually reviewed the abstracts of identified manuscripts meeting prospective eligibility. Qualified full text articles were retrieved and checked their appropriateness against the inclusion and exclusion criteria. The studies must have distinguishable two arms of participants with severe AWS: benzodiazepine (BZD) and phenobarbital (PB), in the acute care setting. Outcomes assessed in this study were regarded as important in the practical management of patients with severe AWS. Final analyses were run on outcome variables where numbers were sufficient to allow statistical analysis. Exclusion criteria included studies that did not have both BZD and PB in separate arms of comparison. We also excluded studies with mild AWS or not in acute care setting.

\section{Type of participants}

Adult (18 years of age or older) patients with AWS were target population for this meta-analysis.

\section{Types of intervention}

Two classes of medications used to treat severe AWS are BZD and PB. They are being assessed in comparison for their effectiveness to control unopposed sympathetic activation associated with AWS, as well as their potential complications related to the treatment.

Types of outcome measures analyzed: There were ten outcome variables analyzed in this meta-analysis. These include: (a) history of DT; (b) initial CIWA-AR score; (c) drug dosages delivered; (d) duration of medical treatment of severe AWS; (e) other adjunct medication usage; (f) ICU length of stay (LOS); (g) hospital LOS; (h) readmission rate; (i) DT or seizures; (j) other complications including endotracheal intubation and mechanical ventilation.

\section{Statistical analysis and risk of bias across studies}

Meta-analysis was performed using the statistical package 'MetaXL'. Odds ratio (OR) was calculated for binary, and weighted mean differences (WMD) for continuous outcome measures. [11] Due to significant heterogeneity among the trials, the random effects model was used to estimate the pooled prevalence with $95 \%$ confidence interval $(\mathrm{Cl})$. The heterogeneity among studies was assessed using the $\mathrm{Q}$ statistic proposed by Cochrane and $\mathrm{I}^{2}$ index introduced by Higgins and Thompson. [12-14] Standard formulas were used to calculate the mean and SD for studies that reported median and inter-quartile range instead, for inclusion in 
the meta-analysis. [15] The paper reports $p$ values for different statistical tests on the study variables to test for hypothesis. In general, the effect is considered to be statistically significant when the $p$ value is small i.e., $p<0.05$.

Included observational studies were assessed using ROBINS-I tool [16] with respect to the following categories: confounding, selection, intervention classification, deviation from intervention, missing data, measurement of outcome, and selection of reported results. RCT trial was assessed using Rob2 tool [17] and Jadad score. (Table 1)

Table 1

Assessment of risk of biases using ROBIN-1 tool.

\begin{tabular}{|c|c|c|c|c|c|c|c|c|}
\hline $\begin{array}{l}\text { Selected } \\
\text { Studies }\end{array}$ & $\begin{array}{l}\text { Overall } \\
\text { Risk }\end{array}$ & Confounding & Selection & $\begin{array}{l}\text { Classification } \\
\text { of } \\
\text { intervention }\end{array}$ & $\begin{array}{l}\text { Deviation } \\
\text { from } \\
\text { intervention }\end{array}$ & $\begin{array}{l}\text { Missing } \\
\text { data }\end{array}$ & $\begin{array}{l}\text { Measurement } \\
\text { of outcome }\end{array}$ & $\begin{array}{l}\text { Selection } \\
\text { of } \\
\text { reported } \\
\text { results }\end{array}$ \\
\hline $\begin{array}{l}\text { Nisavic et } \\
\text { al. [14] }\end{array}$ & Moderate & Moderate & Serious & Moderate & Moderate & Low & Moderate & Moderate \\
\hline $\begin{array}{l}\text { Sullivan } \\
\text { et al. [15] }\end{array}$ & Low & Moderate & Low & Low & Low & Low & Moderate & Low \\
\hline $\begin{array}{l}\text { Tidwell et } \\
\text { al. [13] }\end{array}$ & Low & Moderate & Low & Low & Low & Moderate & Low & Low \\
\hline $\begin{array}{l}\text { Hawa et } \\
\text { al. [19] }\end{array}$ & Low & Moderate & Moderate & Low & Low & Low & Low & Moderate \\
\hline $\begin{array}{l}\text { Nguyen } \\
\text { et al. [17] }\end{array}$ & Moderate & Low & Low & Serious & Moderate & Serious & Low & Moderate \\
\hline $\begin{array}{l}\text { Nelson et } \\
\text { al. [18] }\end{array}$ & Moderate & Moderate & Moderate & Serious & Low & Low & Moderate & Low \\
\hline $\begin{array}{l}\text { Rosenson } \\
\text { et al. [16] }\end{array}$ & RCT. Ove & w-risk asses & using $\mathrm{R}$ & tool and Jad & cale of 4 & & & \\
\hline
\end{tabular}

\section{Results}

\section{Included studies}

Cross-searching of electronic database yielded a total of 355 abstracts. After exclusion of 42 duplicate records and 167 nonrelevant citations, 42 unique citations of potential relevance were retrieved for further review. The process by which these manuscripts and abstracts were excluded is described in Figure 1. No further unpublished studies were found to be suitable to be included in this systematic review and meta-analysis. The seven studies [18-24] that met the inclusion criteria are detailed in Table 2. They collectively demonstrated moderate risk of bias based on ROBINS-1 tool for the first six observational studies, and low risk of bias using Rob2 and Jadad scale for the RCT. [16-17] (Table 1). 
Table 2

Salient features of various trials

\begin{tabular}{|c|c|c|c|c|c|}
\hline $\begin{array}{l}\text { Author /Yr/ } \\
\text { Country[ref] }\end{array}$ & Study Design & $\begin{array}{l}\text { Patients } \\
\text { N }\end{array}$ & BZD & $\begin{array}{l}\text { PB } \\
\text { w or } \\
\text { Wo } \\
\text { BZD } \\
n\end{array}$ & Outcome Measures \\
\hline $\begin{array}{l}\text { Nisavic et } \\
\text { al./2019/USA } \\
{[14]}\end{array}$ & $\begin{array}{l}\text { Retrospective } \\
\text { chart review }\end{array}$ & 562 & 419 & 143 & $\begin{array}{l}\text { Primary: development of AWS-related complications (seizures, } \\
\text { hallucinations, withdrawal delirium) } \\
\text { Secondary: hospital LOS, ICU admission rate and LOS, } \\
\text { medication adverse effects, and discharge against medical } \\
\text { advice }\end{array}$ \\
\hline $\begin{array}{l}\text { Sullivan et } \\
\text { al./2019/USA } \\
\text { [15] }\end{array}$ & $\begin{array}{l}\text { Retrospective } \\
\text { cohort study }\end{array}$ & 209 & 112 & 97 & $\begin{array}{l}\text { Primary outcome: need for ICU admission } \\
\text { Secondary: CIWA scores at ED discharge, and complications } \\
\text { (death, intubation, hypotension/vasopressors, seizures, HAP) }\end{array}$ \\
\hline $\begin{array}{l}\text { Tidwell et } \\
\text { al./2018/USA } \\
\text { [13] }\end{array}$ & $\begin{array}{l}\text { Retrospective } \\
\text { cohort study }\end{array}$ & 120 & 60 & 60 & $\begin{array}{l}\text { Primary outcome: ICU LOS } \\
\text { Secondary: Hospital LOS, intubation, use of adjunct medications }\end{array}$ \\
\hline $\begin{array}{l}\text { Hawa et } \\
\text { al./2021/USA } \\
\text { [19] }\end{array}$ & $\begin{array}{l}\text { Retrospective } \\
\text { cohort study }\end{array}$ & 606 & 543 & 63 & $\begin{array}{l}\text { Primary outcome: hospital LOS } \\
\text { Secondary: 30-day all cause readmission, 30-day alcohol-related } \\
\text { readmission, 30-day ED visits after discharge, and need for ICU } \\
\text { transfer during hospital stay }\end{array}$ \\
\hline $\begin{array}{l}\text { Nguyen et } \\
\text { al./2020/USA } \\
{[17]}\end{array}$ & $\begin{array}{l}\text { Retrospective } \\
\text { cohort study }\end{array}$ & 72 & 36 & 36 & $\begin{array}{l}\text { Primary outcome: total duration of treatment } \\
\text { Secondary outcome: ICU LOS, change in CIWA at 24h, incidence } \\
\text { of hypotension, mechanical ventilation, and serum osm gap }\end{array}$ \\
\hline $\begin{array}{l}\text { Rosenson et } \\
\text { al./2013/USA } \\
{[16]}\end{array}$ & $\begin{array}{l}\text { Prospective, } \\
\text { double blind, } \\
\text { RCT }\end{array}$ & 102 & 51 & 51 & $\begin{array}{l}\text { Primary outcome: initial level of admission (ICU vs telemetry vs } \\
\text { floor ward) }\end{array}$ \\
\hline $\begin{array}{l}\text { Nelson et } \\
\text { al./2019/USA } \\
{[18]}\end{array}$ & $\begin{array}{l}\text { Retrospective, } \\
\text { observational } \\
\text { cohort }\end{array}$ & 300 & 100 & 200 & $\begin{array}{l}\text { Primary outcome: rate of ICU admission } \\
\text { Secondary outcome: mechanical ventilation, hospitalization rate, } \\
\text { total and ICU LOS, total dose of diazepam equivalent, total PB, } \\
\text { and number of protocol violations }\end{array}$ \\
\hline
\end{tabular}

\section{Excluded studies}

We excluded studies outside of acute care setting as these are not of interest of our review. Within eleven suitable citations, three [25-27] were excluded due to inability to separate BZD and PB treatment arms. One [28] was excluded during meta-analysis after reviewing data, due to the absence of BZD treatment group.

\section{Pooled analysis with heterogeneity}

Six retrospective and one randomized control trials with a total of 1971 patients were analyzed. The median age for patients in the BZD group was 49.9 years, and that of patients in the PB group was 47 years. According to six studies [18-23], the pooled prevalence of patients who had a history of DT was $27 \%\left(\mathrm{Cl} 0.95,0.42, \mathrm{I}^{2}=93 \%, \mathrm{n}=204 / 778\right)$ in the BZD group (Figure $\left.2 A\right)$ and $30 \%$ $\left(95 \% \mathrm{Cl} 0.18,0.43, \mathrm{I}^{2}=90 \%, \mathrm{n}=182 / 587\right)$ in the PB group (Figure 2B). Five studies [20-24] reported CIWA-AR. The median CIWA-AR score in patients who received BZD was 9.046 plus minus 5.87, and that in patients who received PB was 10.3 plus minus 7.2 . The Odds ratio between the two groups was statistically insignificant (Figure 3 ). 
We analyzed the outcome of BZD and PB treatment groups in the following three categories: median hospital LOS, median ICU LOS, and the prevalence of DT. The median LOS at the hospital for patients who received BZD was 4.92 (SD 1.49) days, whereas that in patients who received PB was 3.17 (SD 0.625) days. The odds ratio between the two groups was statistically insignificant (Figure 4). The median LOS in ICU was 3.92 (SD 0.95) days in patients who received BZD, and was 2.4 (SD 1.5) days in patients who received PB. (Figure 5) The pooled prevalence of DT or seizures seen in patients who received BZD was $7 \%(95 \% \mathrm{Cl} 0.03,0.11$, $\left.\mathrm{I}^{2}=59 \%, \mathrm{n}=49 / 582\right)$ (Figure $\left.6 \mathrm{~A}\right)$, whereas the pooled prevalence of DT in patients who received PB was $5 \%(95 \% \mathrm{Cl} 0.02,0.08$, $\mathrm{I}^{2}=20 \%, \mathrm{n}=14 / 291$ ) (Figure $6 \mathrm{~B}$ ) as reported by three trials [19-21] in the meta-analysis. The odds ratio however was statistically insignificant between the two groups (Figure 6C).

Finally, we examined complications in both BZD and PB treatment arms for severe AWS. The pooled prevalence of intubation was reported by 5 trials $[18,20-23]$ as $4 \%\left(95 \% \mathrm{Cl} 0.00,0.12, \mathrm{I}^{2}=86 \%, \mathrm{n}=23 / 359\right)$ in the BZD group and $4 \%\left(95 \% \mathrm{Cl} 0.02,0.06, \mathrm{I}^{2}=5 \%\right.$, $n=17 / 444$ ) in the PB group [18] (Figure 7A and 7B). Re-admissions reported in the BZD treatment group were $11.97 \%$, and $9.52 \%$ in the PB treatment group [24]. The prevalence of other adjunct medication usage was reported by three trials $[18,20,21]$ as $50 \%$ in the BZD group ( $\left.95 \% \mathrm{Cl} 0.23,0.76, \mathrm{I}^{2}=93 \%, \mathrm{n}=99 / 223\right)$, and $31 \%\left(95 \% \mathrm{Cl} 0.13,0.52, \mathrm{I}^{2}=88 \%, \mathrm{n}=61 / 208\right)$ in PB group (Figure $8 A$ and $8 B)$.

\section{Publication bias}

It is often challenging to accurately assess publication bias across studies of meta-analysis of observational trials due to inability to track their pre-registration and protocol preparation data [29]. This is a known increased risk of publication bias and other reporting biases such as selective outcome reporting. (Table 1) Even though unpublished data may lead to bias, these studies may be of lower methodological quality and inadequate outcome assessment [30].

\section{Discussion}

BZD has long been preferred and considered as the first-line of treatment in patients with AWS [31]. For those with severe symptoms, cumulative, high doses of BZD are required to control overactive sympathetic tone and associated DT and seizures'. This in turn, can lead to oversedation, respiratory insufficiency, worsening delirium, as well as increased risk of aspiration, intubation, length of stay, and hospital costs [32]. Barbiturates have been touted as an alternative treatment option, especially in patients with refractory episodes of DT, possibly with the drawback of a more pronounced acute toxicity [33]. While barbiturates, specifically phenobarbital, have shown convincing results, they have not been routinely used in the treatment of AWS [34]. The most recent retrospective review by Oks showed promising results of PB as monotherapy for the treatment of severe AWS in medical ICU. [28]

In this systematic review and meta-analysis, we aim to evaluate and analyze available evidence in the use of PB versus BZD to treat severe AWS in acute care setting. We understand that six of seven total of selected citations are not high quality RCTs [18-20, 22-24], yet they offer substantial new evidence since last conducted systematic review and meta-analysis [35-36]. The patients included in our studies had similar baseline characteristics: age, history of DT, and CIWA-AR scores (Figure 2 and 3).

Overall, the results from the included studies suggest that barbiturates alone or in combination with BZD are at least as effective as BZD in the treatment of severe AWS, indicated by comparable prevalence of DT or seizures (Figure 6C). This could be explained by the differences of underlying mechanisms of action between PB and BZD. PB provides adequate GABA agonism and glutamate antagonism for a prolonged duration, in contrast to BZD, which affect only the GABA receptor. Therefore, the more balanced inhibitory profile of PB results in an increased duration of symptom control [8-9]. Other outcome variables such as hospital LOS and ICU LOS are not statistically significant between BZD and PB treatment groups. However, the pooled mean ICU LOS is 2.4 days in PB group and 3.92 in BZD group. The mean hospital LOS is 3.17 days in PB group versus 4.92 in BZD group. Since the financial burden of an ICU stay is typically significant, PB group may offer an advantage of potentially decreasing the overall cost of health care system by a trend towards decrease in LOS in our current analysis.

Many clinicians have reservations about using PB due to concerns regarding their narrow therapeutic window, potential to induce respiratory depression and its long half-life [37-38]. In our analysis, we found the pooled prevalence of endotracheal intubation to 
be $4 \%$ in both treatment options (Figures 7A \& 7B). This is consistent with previous reported finding that PB-related respiratory depression as a rare complication in severe AWS treatment [39]. We, therefore, conclude that the use of PB does not increase the rate of endotracheal intubation when compared to BZD, despite narrower therapeutic window and longer half-life.

The use of additional medications in both BZD and PB arms was also not statistically significant. However, there was a trend of decreasing prevalence in the usage of adjunct medications in PB (0.31) versus BZD group (0.5) (Figure 8A and 8B). This finding offers a potential advantage of PB use over BZD as less adjunct medications in PB group may limit extra costs and possible drugdrug interactions. Additionally, PB was shown to decrease the need for continuous infusion of BZD, lower the overall drug requirement, and can be used as an adjunct agent in patients who require high doses of BZD [40].

\section{Limitations}

The previously referenced studies in this systematic review and meta-analysis have several limitations. First of all, six of seven selected citations are retrospective trials that are susceptible to confounding factors by study design. Secondly, there are areas of heterogeneity among the selected studies. For example, the varying administration methods (fixed versus symptom-driven) and dosages of both PB and BZD are based on the discretion of the supervising clinician and institution-specific CIWA-Ar protocols, limit the clinical application of the findings [41]. Symptom-triggered BZD regimen has been shown to result in the administration of less total medication and to require a shorter duration of treatment compared to fixed-schedule regimen [42]. The lack of standardization for the use of alternative treatments in patients with severe AWS, namely phenobarbital, due to the absence of guideline recommendations, is a major limitation.

\section{Conclusions}

In conclusion, based on our systematic review and meta-analysis, monotherapy or rescue use as an adjunct of phenobarbital is non-inferior to traditionally administered benzodiazepine in the treatment of severe alcohol withdrawal. Barbiturates also have comparable safety profile and may reduce costs by a trend towards less adjunct medications use and shortened ICU and hospital stay. Large, prospective randomized clinical trials are needed to further investigate PB as the primary treatment of AWS that presents with severe features.

\section{Declarations}

Conflicts of Interest. The above listed authors, Drs. Asllanaj, Chang, Hassan, and McWhorter have no conflicts of interest to declare.

Funding: This research was supported (in whole or in part) by HCA Healthcare and/or an HCA Healthcare affiliated entity. The views expressed in this publication represent those of the author(s) and do not necessarily represent the official views of HCA Healthcare or any of its affiliated entities.

\section{References}

1. SAMHSA, Center for Behavioral Health Statistics and Quality. 2019 National Survey on Drug Use and Health. Table 2.19B Alcohol Use in Past Month among Persons Aged 12 or Older, by Age Group and Demographic Characteristics: Percentages, 2018 and 2019.

2. Wood E, Albarqouni L, Tkachuk S, Green CJ, Ahamad K, Nolan S, McLean M, Klimas J. Will This Hospitalized Patient Develop Severe Alcohol Withdrawal Syndrome?: The Rational Clinical Examination Systematic Review. JAMA. 2018 Aug 28;320(8):825833.

3. McKeown NJ, West PL. What is the mortality and morbidity of alcohol withdrawal syndrome? Medscape. 2018.

4. Saitz R, Mayo-Smith MF, Roberts MS, Redmond HA, Bernard DR, Calkins DR: Individualized treatment for alcohol withdrawal. A randomized double-blind controlled trial. JAMA. 1994, 272:519-523.

5. Sullivan JT, Sykora K, Schneiderman J, Naranjo CA, Sellers EM. Assessment of alcohol withdrawal: the revised Clinical Institute Withdrawal Assessment for Alcohol scale (CIWA-Ar). Br J Addict. 1989;84:1353-7. 
6. Mirijello, A., D'Angelo, C., Ferrulli, A., Vassallo, G., Antonelli, M., Caputo, F., Leggio, L., Gasbarrini, A., \& Addolorato, G. (2015). Identification and management of alcohol withdrawal syndrome. Drugs, 75(4), 353-365.

7. Poulos CX, Zack M. Low-dose diazepam primes motivation for alcohol and alcohol-related semantic networks in problem drinkers. Behav Pharmacol. 2004, 15:503-512.

8. Hack JB, Hoffmann RS, Nelson LS. Resistant alcohol withdrawal: does an unexpectedly large sedative requirement identify these patients early? J Med Toxicol. 2006;2(2):55-60.

9. Kwan P, Brodie MJ: Phenobarbital for the treatment of epilepsy in the $21^{\text {st }}$ century: a critical review. Epilepsia 2004; 45: pp. 1141-1149.

10. Page MJ, McKenzie JE, Bossuyt PM, Boutron I, Hoffmann TC, Mulrow CD, et al. The PRISMA 2020 statement: an updated guideline for reporting systematic reviews. BMJ 2021;372:n71. doi: 10.1136/bmj.n71

11. Meta-Analysis - Methods for Health and Experimental Studies | Shahjahan Khan | Springer [Internet]. [cited 2020 Nov 6]. Available from: https://www.springer.com/gp/book/9789811550317

12. Cochran WG. The Combination of Estimates from Different Experiments. Biometrics. 1954 Mar;10(1):101.

13. Higgins JPT, Thompson SG. Quantifying heterogeneity in a meta-analysis. Stat Med [Internet]. 2002 Jun 15 [cited 2021 Feb 15];21(11):1539-58. Available from: https://pubmed.ncbi.nIm.nih.gov/12111919/

14. Huedo-Medina TB, Sánchez-Meca J, Marín-Martínez F, Botella J. Assessing heterogeneity in meta-analysis: Q statistic or I 2 Index? Psychol Methods [Internet]. 2006 Jun [cited 2021 Feb 15];11(2):193-206. Available from:

https://pubmed.ncbi.nlm.nih.gov/16784338/

15. Hozo SP, Djulbegovic B, Hozo I. Estimating the mean and variance from the median, range, and the size of a sample. BMC Med Res Methodol [Internet]. 2005 Apr 20 [cited 2021 Feb 15];5(1):13. Available from:

http://bmcmedresmethodol.biomedcentral.com/articles/10.1186/1471-2288-5-13

16. Sterne JAC, Hernán MA, Reeves BC, Savović J, Berkman ND, Viswanathan M, Henry D, Altman DG, Ansari MT, Boutron I, Carpenter JR, Chan AW, Churchill R, Deeks JJ, Hróbjartsson A, Kirkham J, Jüni P, Loke YK, Pigott TD, Ramsay CR, Regidor D, Rothstein HR, Sandhu L, Santaguida PL, Schünemann HJ, Shea B, Shrier I, Tugwell P, Turner L, Valentine JC, Waddington H, Waters E, Wells GA, Whiting PF, Higgins JPT. ROBINS-l: a tool for assessing risk of bias in non-randomized studies of interventions. BMJ 2016; 355; i4919; doi: 10.1136/bmj.i4919.

17. Sterne JAC, Savović J, Page MJ, Elbers RG, Blencowe NS, Boutron I, Cates CJ, Cheng H-Y, Corbett MS, Eldridge SM, Hernán MA, Hopewell S, Hróbjartsson A, Junqueira DR, Jüni P, Kirkham JJ, Lasserson T, Li T, McAleenan A, Reeves BC, Shepperd S, Shrier I, Stewart LA, Tilling K, White IR, Whiting PF, Higgins JPT. RoB 2: a revised tool for assessing risk of bias in randomised trials. BMJ 2019; 366: 14898.

18. Tidwell WP, Thomas TL, Pouliot JD, Canonico AE, Webber AJ; Treatment of Alcohol Withdrawal Syndrome: Phenobarbital vs CIWA-Ar Protocol. Am J Crit Care 1 November 2018; 27 (6): 454-460.

19. Nisavic M., Nejad, S., Isenberg, B., Bajwa,E., Currier, P., Wallace, P., Velmahos, G., \& Wilens, T. Use of Phenobarbital in Alcohol Withdrawal Management - A Retrospective Comparison Study of Phenobarbital and Benzodiazepines for Acute Alcohol Withdrawal Management in General Medical Patients, Psychosomatics, Volume 60, Issue 5, 2019, Pages 458-467.

20. Sullivan S., Dewey B., Jarrell D., Vadiei N, Patanwala, A. Comparison of phenobarbital-adjunct versus benzodiazepine-only approach for alcohol withdrawal syndrome in the ED, The American Journal of Emergency Medicine, Volume 37, Issue 7, 2019, Pages 1313-1316.

21. Rosenson J., Clements C., Simon B., Vieaux J., Graffman S., Vahidnia F., et. Al.: Phenobarbital for acute alcohol withdrawal: A prospective randomized double-blind placebo-controlled study. Journal of Emergency Medicine 2013; 44: pp. 592-598.

22. Nguyen, T. \& Lam, S. Phenobarbital and symptom-triggered lorazepam versus lorazepam alone for severe alcohol withdrawal in the intensive care unit, Alcohol, Volume 82, 2020, pages 23-27.

23. Nelson, A., Kehoe, J., Sankoff, J., Mintzer, D., Taub, J., Kaucher, K. Benzodiazepines vs barbiturates for alcohol withdrawal: Analysis of 3 different treatment protocols. The American Journal of Emergency Medicine, Volume 37, Issue 4, 2019, Pages 733-736.

24. Hawa F, Gilbert L, Gilbert B, et al. (February 11, 2021) Phenobarbital Versus Lorazepam for Management of Alcohol Withdrawal Syndrome: A Retrospective Cohort Study. Cureus 13(2): e13282. 
25. Duby, JJ, Berry AJ, Ghayyem P, Wilson MD, Cocanour, CS. Alcohol Withdrawal Syndrome in Critically III Patients: Protocolized vs Non-protocolized Management. J Trauma Acute Care Surg. 2014 December ; 77(6): 938-943.

doi:10.1097/TA.0000000000000352.

26. Gold JA, Rimal B, Nolan A, Nelson LS. A strategy of escalating doses of benzodiazepines and phenobarbital administration reduces the need for mechanical ventilation in delirium tremens. Crit care med. 2007 March; 35(3): 724-730. doi:10.1097/01.CCM.0000256841.28351.80.

27. Lee JA, Duby JJ, Cocanour CS. Effect of early and focused benzodiazepine therapy on length of stay in severe alcohol withdrawal syndrome. Clin Toxicol (Phila). 2019 Jull;57(7):624-627. doi: 10.1080/15563650.2018.1542701.

28. Oks M, Cleven KL, Healy L, Wei M, Narasimhan M, Mayo PH, Kohn N, Koenig S. The safety and utility of phenobbarbital use for the treatment of severe alcohol withdrawal syndrome in the medical intensive care unit. Journal of Intensive Care Medicine 2020, Vol. 35(9) 844-850. DOI: 10.1177/0885066618783947.

29. Metelli S, Chaimani A. Evid Based Ment Health 2020;23:83-87. doi:10.1136/ebmental-2019-300129

30. Egger M, Juni P, Bartlett C, Holenstein F, Sterne J. How important are comprehensive literature searches and the assessment of trial quality in systematic reviews? Empirical study. Health Technol Assess. 2003;7(1):1-76. PMID: 12583822.

31. McKeon A, Frye MA, Delanty N. The alcohol withdrawal syndrome. J Neurol Neurosurg Psychiatry. 2008;79:854-862.

32. Gertler R, Brown HC, Mitchell DH, Silvius EN. Dexmedetomidine: a novel sedative-analgesic agent. Proc (Bayl Univ Med Cent). 2001;14(1):13-21.

33. Hack JB, Hoffmann RS, Nelson LS. Resistant alcohol withdrawal: does an unexpectedly large sedative requirement identify these patients early? J Med Toxicol. 2006;2:55.

34. Hjermo I., Anderson J.E., Fink-Jensen A., Allerup P., Ulrichsen J.: Phenobarbital versus diazepam for delirium tremens- a retrospective study. Dan Med Bull 2010; 57: pp. A4169.

35. Hammond DA, Rowe JM, Wong A, Wiley TL, Lee KC, Kane-Gill SL. Patient Outcomes Associated With Phenobarbital Use With or Without Benzodiazepines for Alcohol Withdrawal Syndrome: A Systematic Review. Hosp Pharm. 2017 Oct;52(9):607-616. doi: 10.1177/0018578717720310. Epub 2017 Jul 17. PMID: $29276297 ;$ PMCID: PMC5735736.

36. Mo Y, Thomas MC, Karras GE Jr. Barbiturates for the treatment of alcohol withdrawal syndrome: A systematic review of clinical trials. J Crit Care. 2016 Apr;32:101-7. doi: 10.1016/j.jcrc.2015.11.022. Epub 2015 Dec 8. PMID: 26795441.

37. Awissi DK, Lebrun G, Coursin DB, et al. Alcohol withdrawal and delirium tremens in the critically ill: a systematic review and commentary. Intensive Care Med. 2013;39(1):16-30.

38. Daniell LC. Effect of anesthetic and convulsant barbiturates on N-methyl-D-aspartate receptor-mediated calcium flux in brain membrane vesicles. Pharmacology. 1994;49:296-307.

39. Young GP, Rores C, Murphy C, et al. Intravenous phenobarbital for alcohol withdrawal and convulsions. Ann Emerg Med. 1987;16(8):847-850.

40. Hendey GW, Dery RA, Barnes RL, Snowden B, Mentler P. A prospective, randomized, trial of phenobarbital versus benzodiazepines for acute alcohol withdrawal. Am J Emerg Med. 2011;29:382-385.

41. Mayo-Smith MF. Pharmacological management of alcohol withdrawal. A meta-analysis and evidence-based practice guideline. American Society of Addiction Medicine Working Group on Pharmacological Management of Alcohol Withdrawal. JAMA. 1997;278:144-51.

42. Daeppen JB, Gache P, Landry U, Sekera E, Schweizer V, Gloor S, et al. Symptom-triggered vs fixed-schedule doses of benzodiazepine for alcohol withdrawal: a randomized treatment trial. Arch Intern Med. 2002;162:1117-21.

\section{Figures}




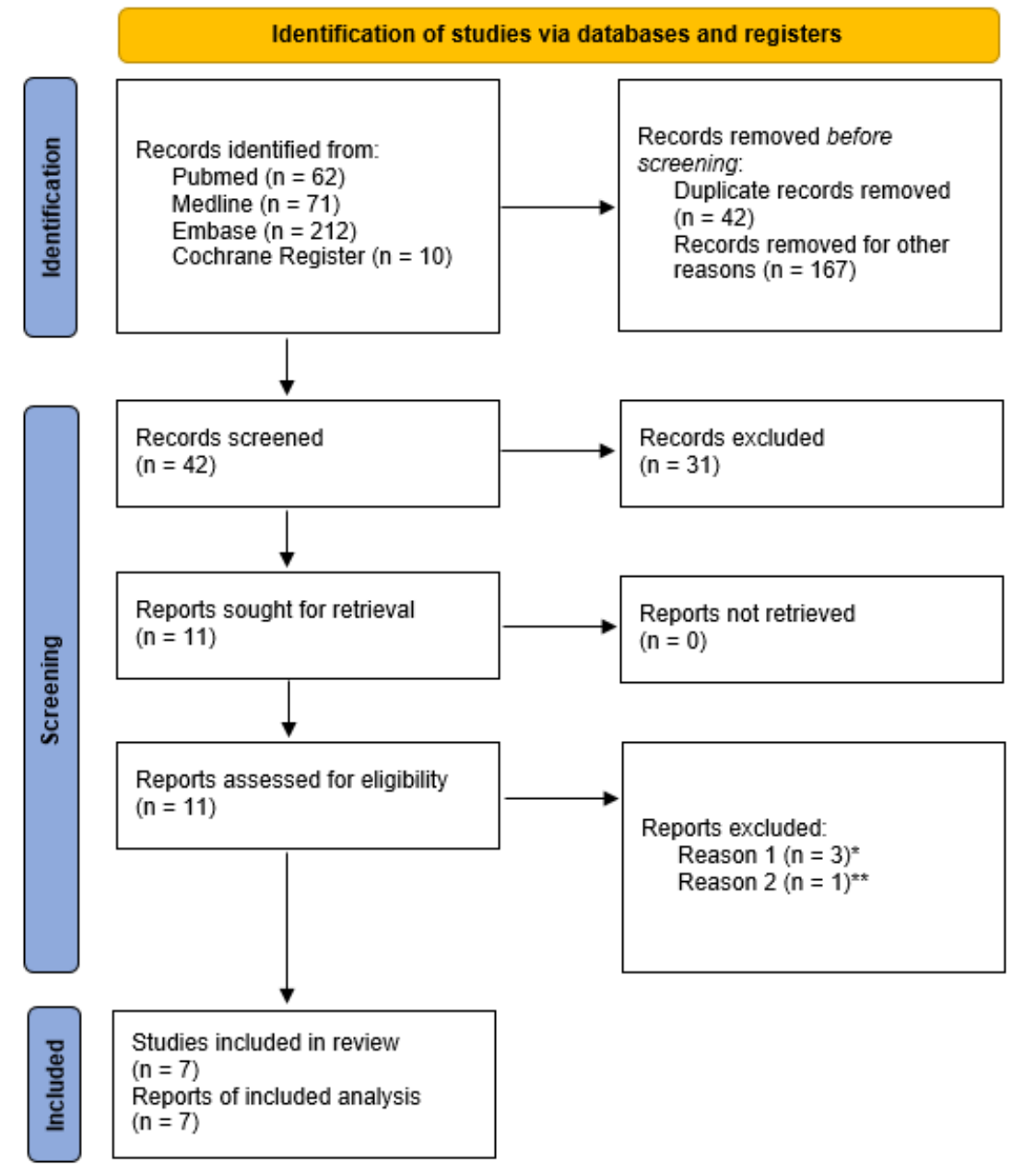

Figure 1

PRISMA Diagram. *The study arms by Duby, Gold, and Lee were unable to be separated into distinctive phenobarbital versus nonphenobarbital to be included in the final analysis [25-27]. ** Oks et al only contains only phenobarbital arm for the treatment of severe acute alcohol withdrawal; therefore, it is excluded in the final meta-analysis [28]. 


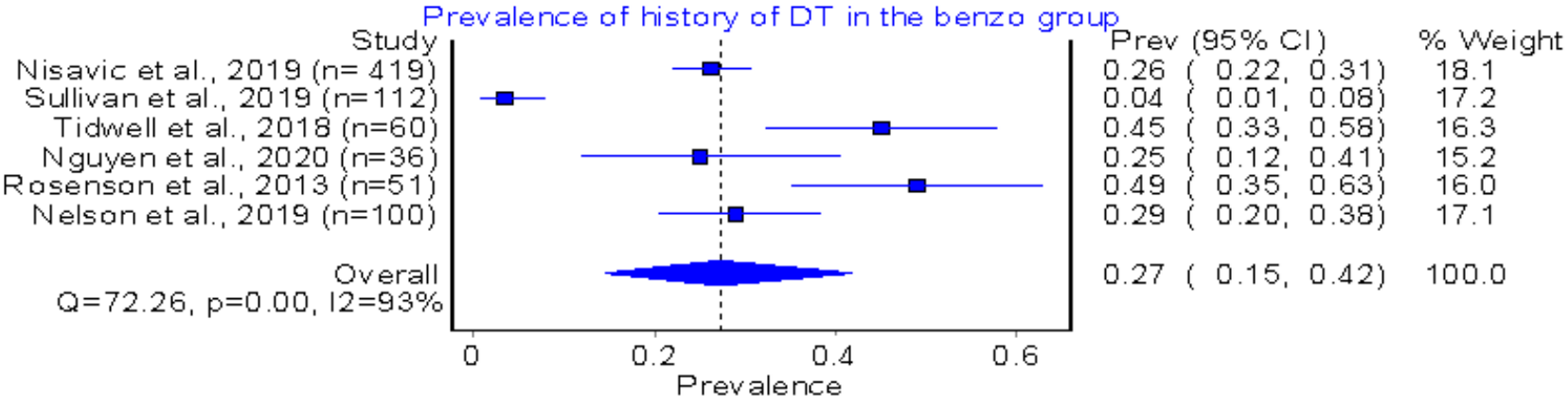

A

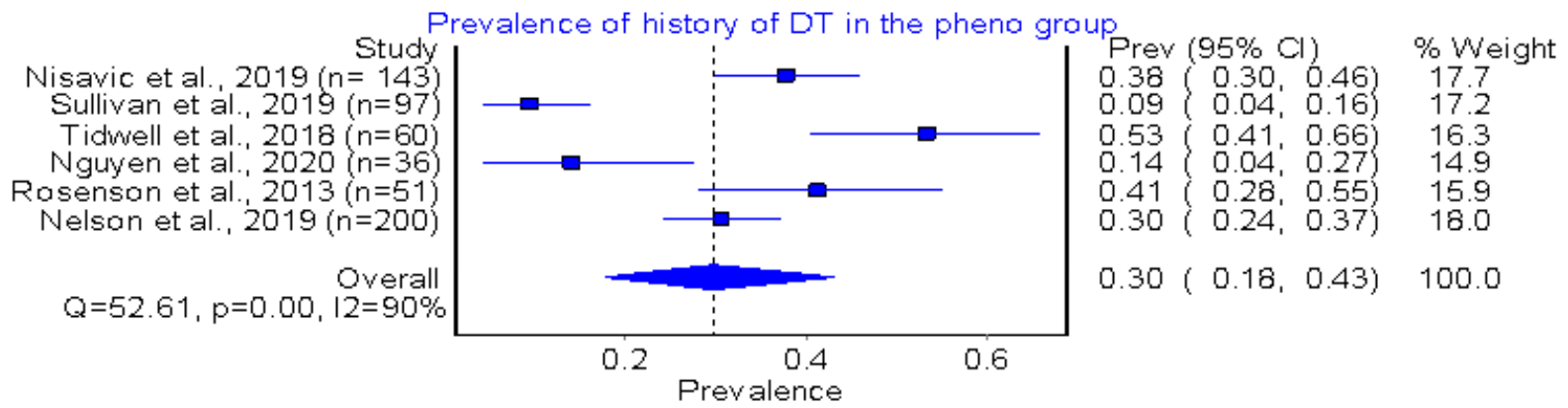

B

Figure 2

A Prevalence of history of DT in the BZD group B Prevalence of history of DT in the PB group

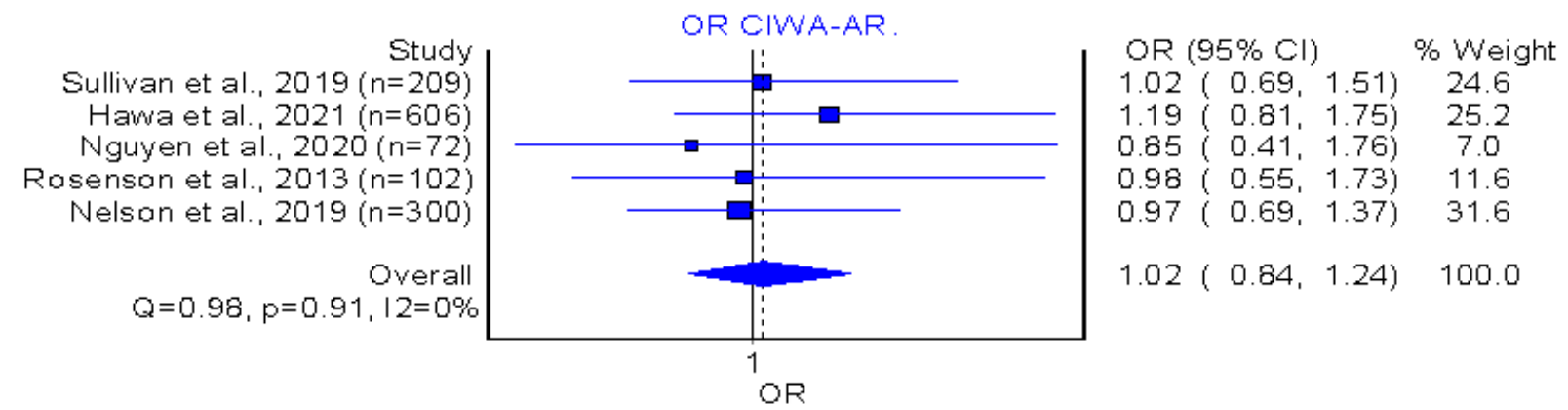

Figure 3

Odds Ratio of CIWA-AR score between the BZD and PB group 


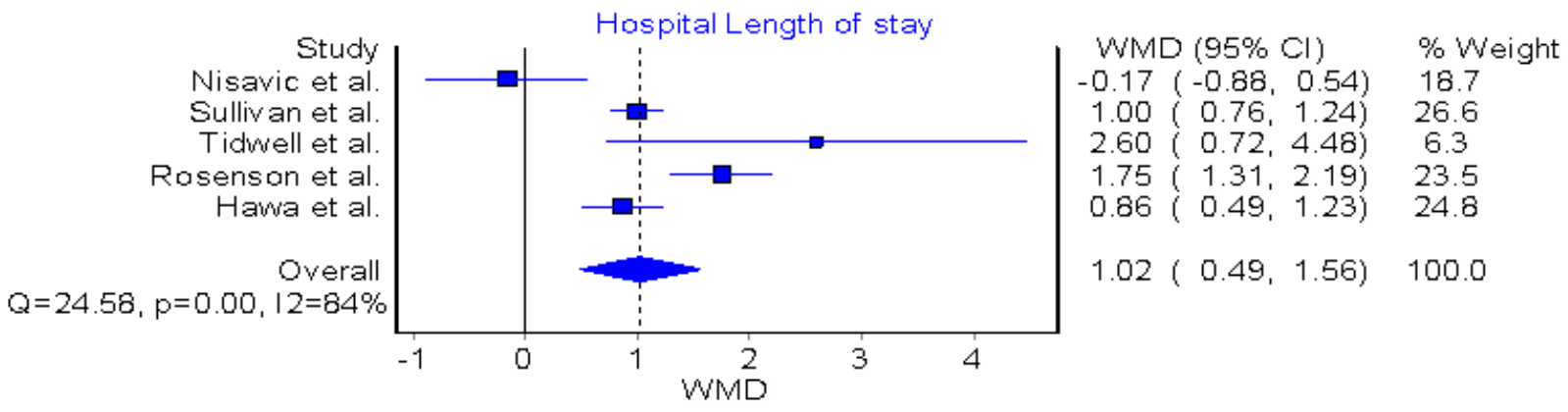

Figure 4

Hospital LOS between the BZD and PB group

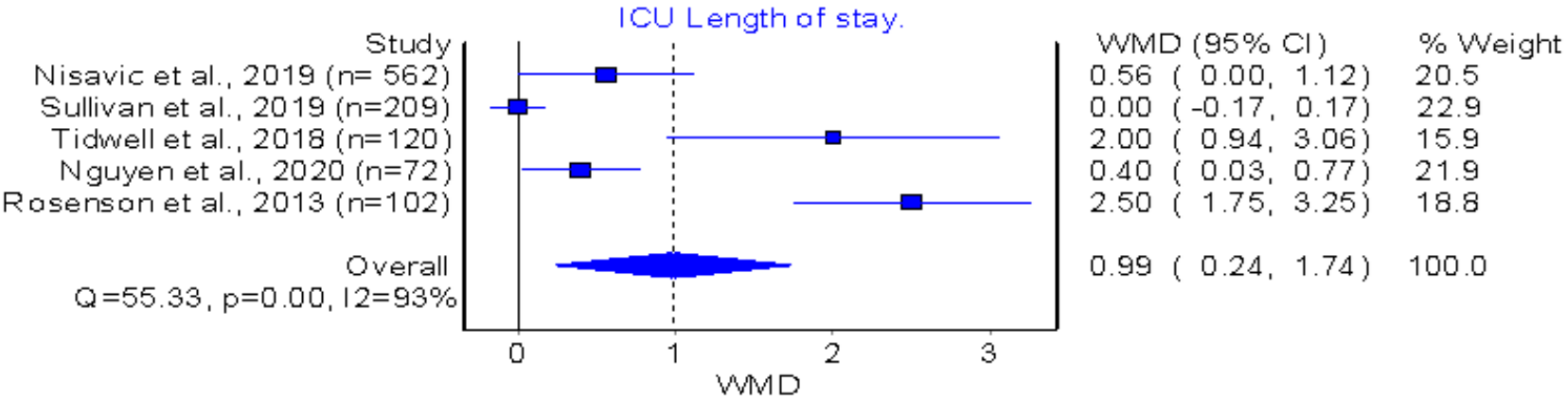

Figure 5

ICU LOS between the BZD and PB group 


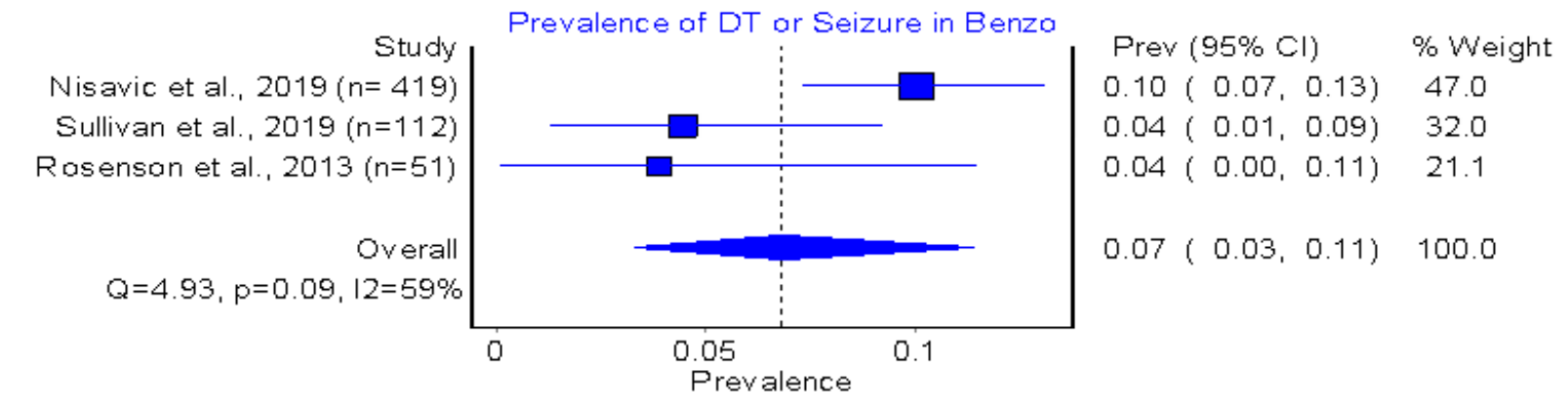

A

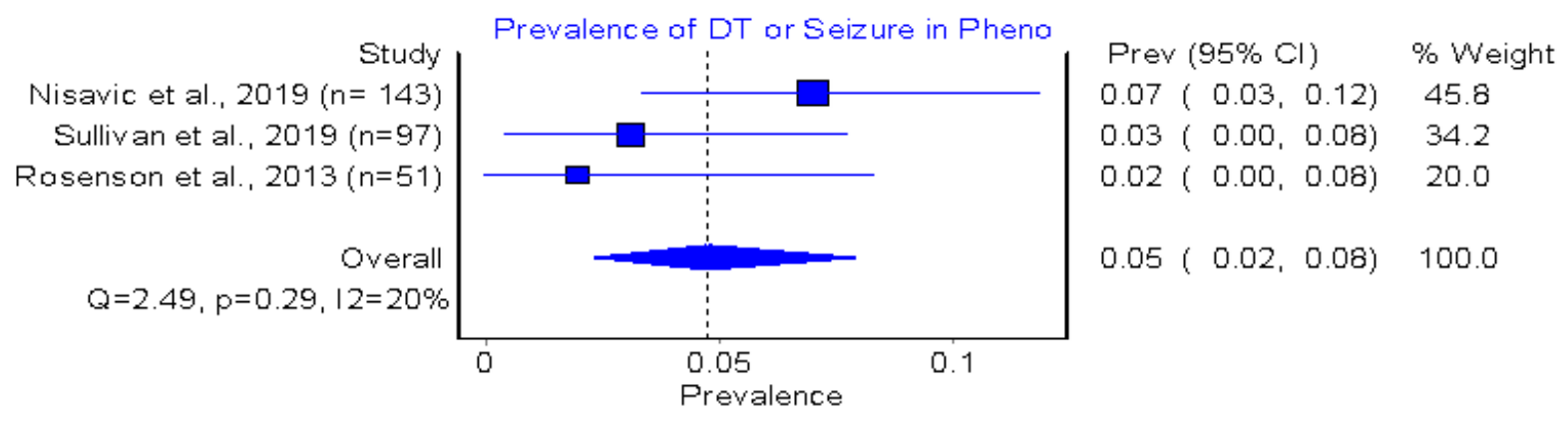

B

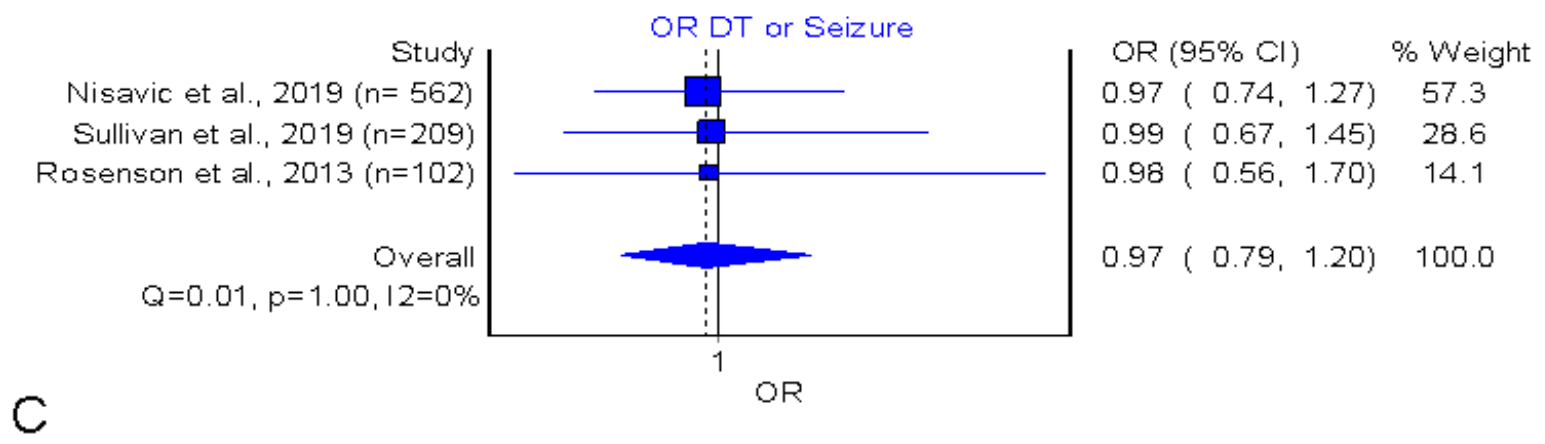

\section{Figure 6}

A The prevalence of DT or seizure in BZD group B The prevalence of DT or seizure in PB group C Odds Ratio of DT or seizure score between the BZD and PB group 
A

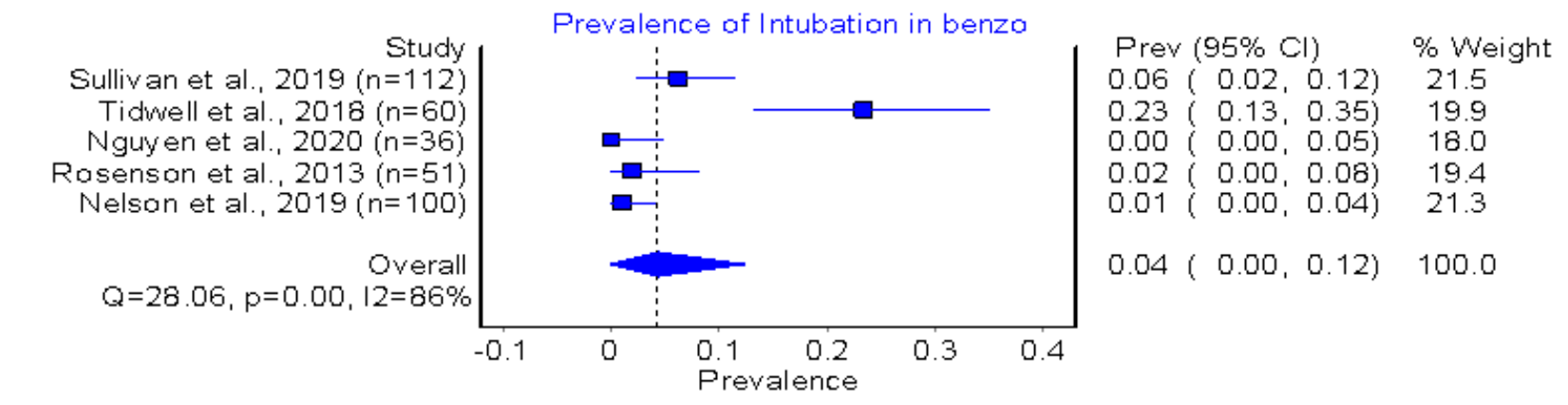

B

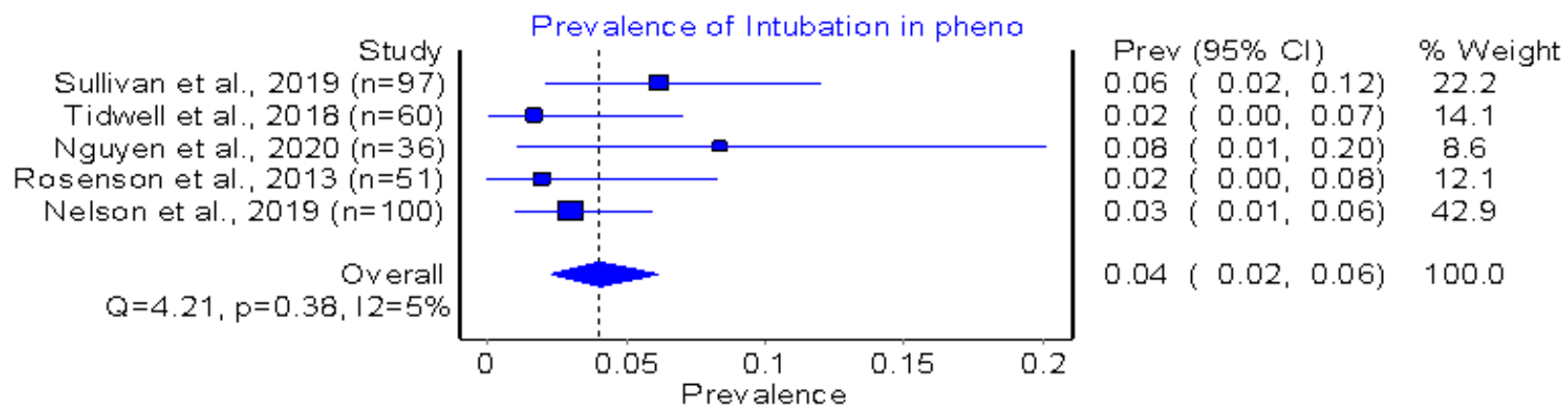

Figure 7

A The prevalence of intubation in BZD group B The prevalence of intubation in PB group

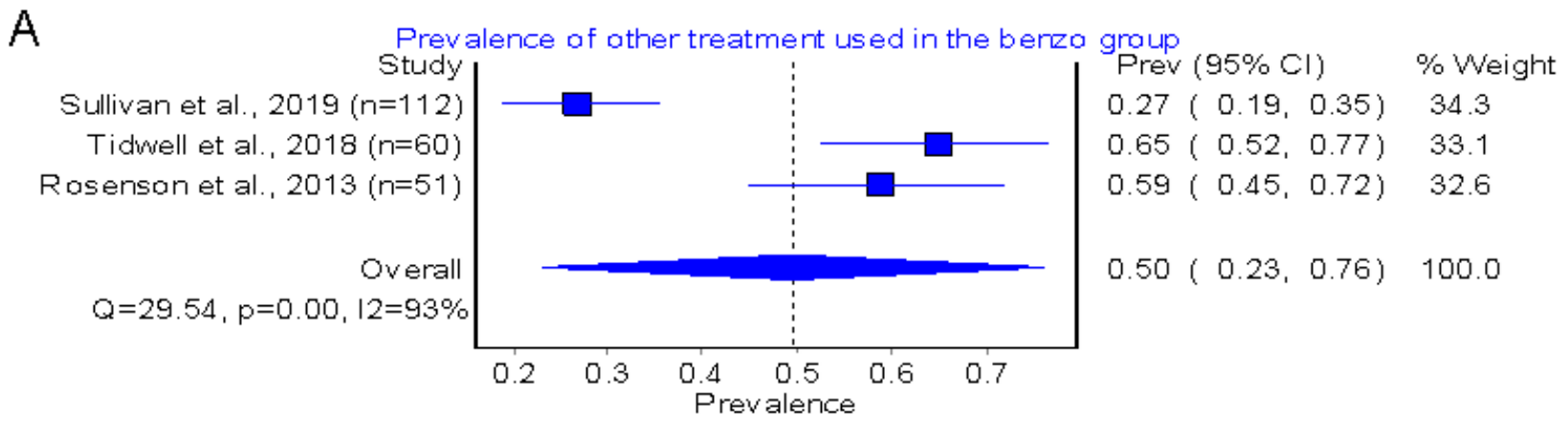

B

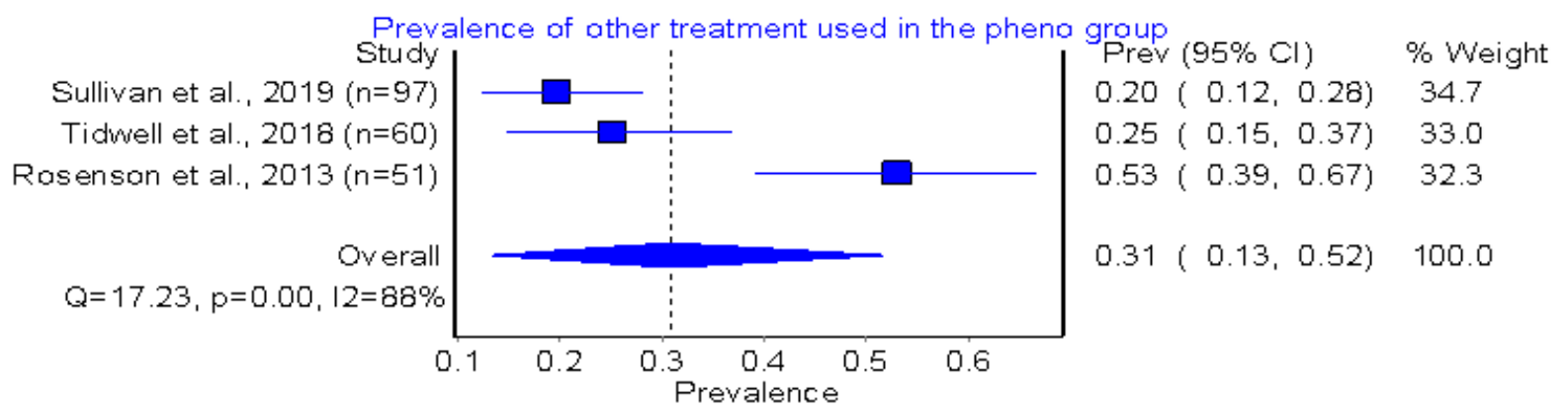


Figure 8

A The prevalence of adjunct medication usage in BZD group B The prevalence of adjunct medication usage in PB group 